\title{
HYPOTHESIS
}

\section{Weaning children with accommodative esotropia out of spectacles: a pilot study}

\author{
K A Hutcheson, N J Ellish, S R Lambert
}

Br J Ophthalmol 2003;87:4-7

See end of article for authors' affiliations

.....................

Correspondence to: Scott Lambert, MD, Emory Eye Center, 1365-B Clifton Road, NE Atlanta, GA 30322, USA

slamber@emory.edu

Accepted for publication 25 March 2002

\begin{abstract}
Background/aim: Many children with accommodative esotropia must continue spectacle use throughout life. This study was undertaken to determine which factors are predictive of successfully weaning children with accommodative esotropia out of spectacles.

Methods: A retrospective review of 10 children with accommodative esotropia, who were gradually weaned from their hyperopic correction, and three age matched controls was performed. The main outcome measure was resolution or non-resolution of esotropia following weaning and eventual discontinuation of spectacles. Secondary outcome measures were final refractive error and the final esotropic or esophoric angle without correction.

Results: Six patients were successfully weaned from spectacles. At the completion of the weaning period one child was orthophoric and the other five children had well controlled esophorias. The other four patients remained spectacle dependent because of persistent esotropia or decreased vision without spectacles. The baseline and final refractive errors were significantly lower in the children successfully weaned from spectacles $(p=0.014)$. While the children who were successfully weaned from spectacles were older when initially diagnosed with accommodative esotropia (4.6 $\vee 2.5$ years), this difference was not statistically significant $(p=0.09)$.

Conclusion: Some children with accommodative esotropia may be weaned out of spectacles during the grade school years with resolution of their esotropia. It is likely that gradual reduction of the hyperopic correction increases divergence amplitudes, but it is unclear whether this facilitates emmetropisation.
\end{abstract}

\section{MATERIALS AND METHODS}

A retrospective review was performed on a group of children with accommodative esotropia who were followed at the Emory Eye Center from January 1989 to August 1998. Beginning in August 1995, an attempt was made to wean children from spectacles with 2-5 dioptres of hyperopia, 20/25 or better vision in each eye, and at least 240 seconds of arc stereopsis, provided that they had remained orthotropic while wearing their full hyperopic correction for at least 1 year. Exclusion criteria were: amblyopia ( $\geqslant 2$ lines of interocular difference in best corrected visual acuity), 2 dioptres or more of anisometropia, previous strabismus surgery, prematurity, or neurological abnormalities.

A group of children with the same inclusion and exclusion criteria who were treated before August 1995 and who had not been subjected to any attempts to gradually reduce their hyperopic correction were used as controls. All of these patients were treated longitudinally in the clinical practice of one of the authors (SRL).

Cycloplegic refractive errors were determined 30-45 minutes after the instillation of cyclopentolate $1 \%$ eye drops. Children were initially prescribed their full cycloplegic refraction. If the esotropia persisted or recurred, the cycloplegic refraction was repeated and if additional uncorrected hyperopia was found, the spectacle correction was increased. A high accommodative convergence/accommodation (AC/A) ratio was defined as an esotropia that was 10 prism dioptres (PD) or greater when fixating on a target $33 \mathrm{~cm}$ away than the esotropia when fixating on a target 6 metres away. Stereopsis was measured using the TNO test.

Weaning was accomplished by decreasing the hyperopic correction in $0.50 \mathrm{D}$ or $1.00 \mathrm{D}$ increments. The hyperopic correction was reduced only if the child was orthotropic at distance and near with his current spectacle correction, and he remained aligned with the reduced correction when tested in the office with trial lenses. Follow up visits were performed at 6 month intervals. A child was considered to have been weaned successfully if he or she was orthotropic without spectacles when fixating both in the distance and near and had at least 20/25 visual acuity in each eye without symptoms of asthenopia. Patients with a large symptomatic phoria or intermittent esotropia were not considered to have been weaned successfully. 


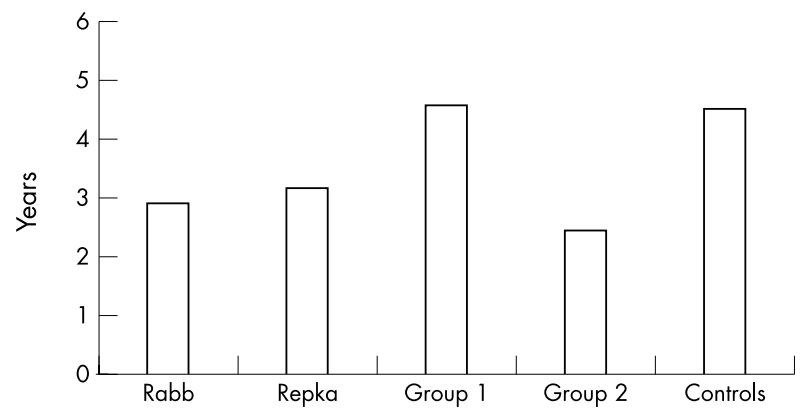

Figure 1 Age spectacle wear initiated for study (group 1, spectacles discontinued; group 2, spectacles still worn) and control patients compared to accommodative esotropes reported by Raab and Repka. ${ }^{2}$

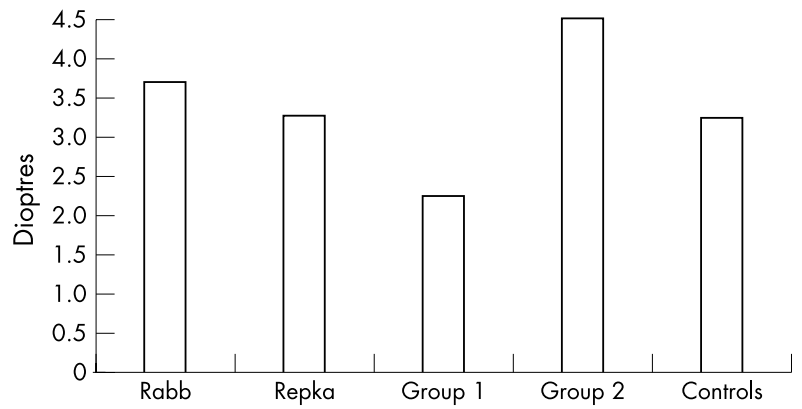

Figure 2 Initial refractive error for study (group 1, spectacles discontinued; group 2, spectacles still worn) and control patients compared to accommodative esotropes reported by Raab' and Repka. $^{2}$

Because our data are non-normative, and given the small sample size, results are reported as medians rather than means. Statistical comparisons were performed using the Wilcoxon rank sum test.

\section{RESULTS}

\section{Group $1(n=6)$}

Six children who were subjected to weaning were able to discontinue spectacle wear by the end of the study period. These children had a median age of 4.6 years (range $2.5-6.0$ years) (Fig 1) at the time spectacle wear was initiated and baseline hyperopia of $+2.25 \mathrm{D}$ (range +1.75 to $+2.80 \mathrm{D}$ ) (Fig 2 ). The baseline esotropic angle was 22.5 PD (range 10-25 PD). Five of the six children had a normal baseline AC/A ratio. They had an initial increase in their hyperopic refractive error of $+1.00 \mathrm{D}$, and a subsequent mean decrease of $-1.70 \mathrm{D}$ over a median period of 3.75 years while wearing spectacles (Fig 3). The peak refractive error was $+3.25 \mathrm{D}$ and the final refractive error at the time of spectacle discontinuation was $+1.56 \mathrm{D}$ (range 0.0 $\mathrm{D}$ to $+3.06 \mathrm{D})$. The rate of decline in hyperopia was $-0.5 \mathrm{l}$ $\mathrm{D} /$ year. Median astigmatism averaged over the study period was $+0.18 \mathrm{D}$, and the median peak astigmatism was +0.20 D. The one child with a high AC/A ratio wore bifocals for 1 year until the AC/A ratio normalised. Final median stereoacuity was 45 seconds of arc (range 30-120 seconds). The final median strabismic angle, uncorrected, was 13 PD of esophoria (range 0-20 PD). One child was orthophoric and the other five children had excellent control of their esophorias. The final $\mathrm{AC} / \mathrm{A}$ ratio remained unchanged in four children, increased in one child, and decreased in one child. Weaning was commenced at a median age of 6.3 years and completed by a median of 9.0 years (Fig 4). These children had been out of glasses for a median of 1.6 years at the end of the follow up period.

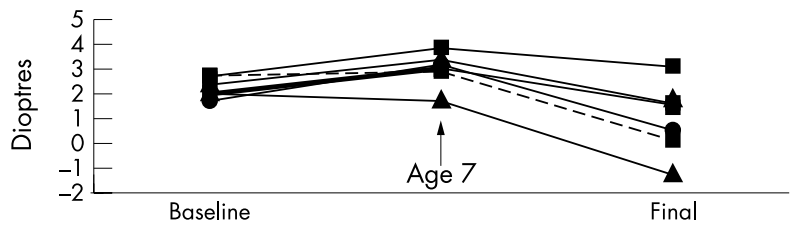

Figure 3 Change in hyperopia in group 1 patients.

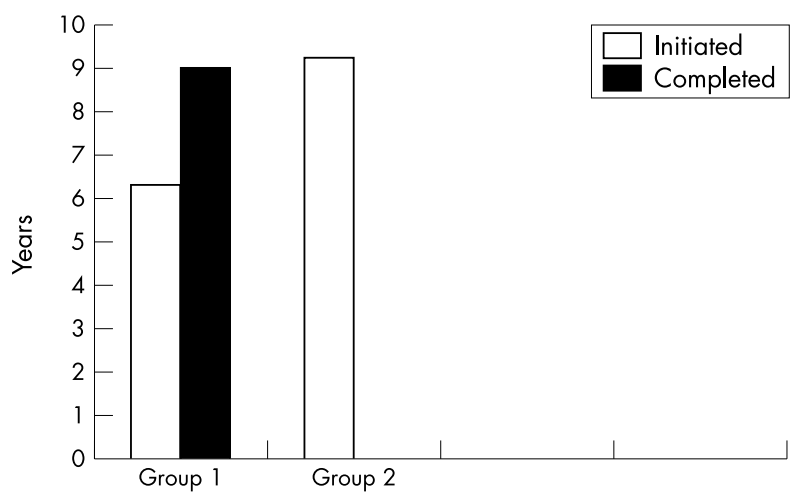

Figure 4 Age weaning initiated and completed for group 1 and 2 patients.

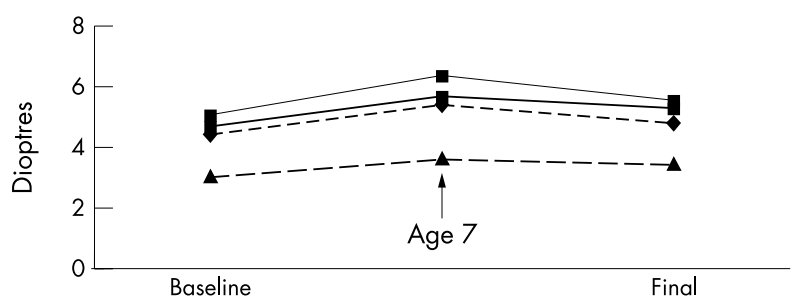

Figure 5 Changes in hyperopia in group 2 patients.

\section{Group $2(n=4)$}

The children who were still dependent upon spectacles at the completion of the study period were a median age of 2.5 years at the time they were initially treated for their accommodative esotropia with spectacles (range 2.0-4.5 years) (Fig 1). Their baseline hyperopia was $+4.50 \mathrm{D}$ (range +3.00 to $+5.00 \mathrm{D}$ ) (Fig 2). Their baseline esotropic angle was 30 PD (range 20-40 PD). All of the children had a normal baseline AC/A ratio. Their hyperopia peaked at $+5.55 \mathrm{D}$ and by the completion of the study had declined to a median of $+5.05 \mathrm{D}$ (Fig 5). The rate of decline in hyperopia from the peak to the final value was -0.07 $\mathrm{D} / \mathrm{year}$. The final spectacle prescription worn was a median of $-1.52 \mathrm{D}$ less than their full cycloplegic refraction. The median final astigmatic refractive error was $+1.84 \mathrm{D}$, and the peak astigmatism for any child at any visit was $+2.75 \mathrm{D}$. The median final stereoacuity was 45 seconds of arc (range 15-60 seconds of arc). The final esotropic angle, without correction, was 17 PD (range 10-25 PD). One child had an intermittent esotropia; the other three children continued to have a constant esotropia without spectacles. The final AC/A ratio was relatively unchanged in three children and decreased in one child. Weaning was commenced at a median age of 9.3 years (Fig 4). At the completion of the study, these children had worn glasses for a median of 6.3 years.

\section{Control group $(n=3)$}

The three control children were initially treated for their accommodative esotropia with spectacles at a median age of 4.5 years (Fig 1). Their baseline refractive error was $+3.25 \mathrm{D}$ (range +2.00 to $+3.67 \mathrm{D}$ ) (Fig 2 ). Their baseline esotropia was 30 PD (range 20-35 PD). After a follow up period of 5 years 


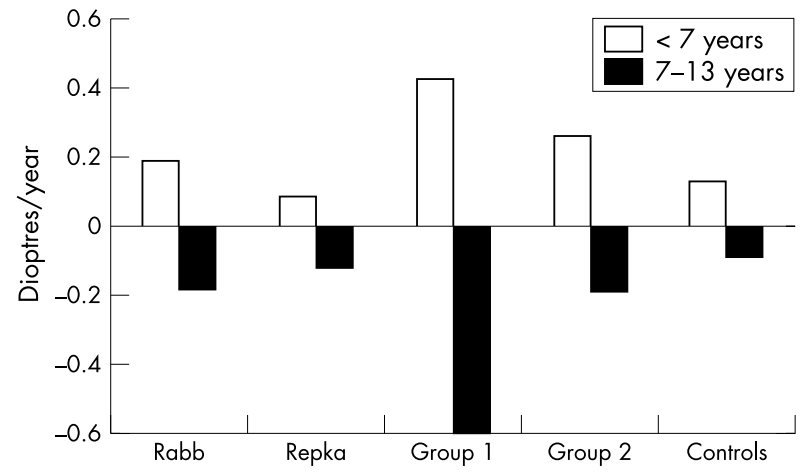

Figure 6 The annual rate of refractive change in study (group 1, spectacles discontinued; group 2, spectacles still worn) and control patients compared to accommodative esotropes reported by Raab' and Repka. ${ }^{2}$

(range 3.5-7 years) these children had a final refractive error of $+3.88 \mathrm{D}$ (range +2.75 to $+4.50 \mathrm{D}$ ). They had a slight increase in hyperopia of $+0.18 \mathrm{D} /$ year before age 7 years and a slight decline of $-0.12 \mathrm{D} /$ year after age 7 years (Fig 6). Median final stereoacuity was 40 seconds of arc (range 30-100 seconds of arc). The final esotropic angle, without correction, was 35 PD (range, 30-35 PD). Over the course of the study, the median uncorrected esotropic angle increased by 5 PD.

The baseline hyperopia in the children who discontinued spectacle wear (group 1) was less than the children who continued to require spectacles (group 2) $(+2.25 v+4.50 \mathrm{D})(\mathrm{p}=$ $0.014)$. The median final refractive error was also significantly lower in group 1 , compared to group $2(+1.56 \mathrm{D} v+5.05 \mathrm{D})(\mathrm{p}$ $=0.014)$. Although the children in group 1 tended to be an older age when diagnosed with accommodative esotropia than the children in group $2(4.6 v 2.5$ years $)$, the difference was not statistically significant $(\mathrm{p}=0.09)$.

Hyperopia increased steadily and rapidly before the age of 7 years for the children in group $1(+0.43 \mathrm{D} /$ year $)$, and then declined rapidly ( $-0.6 \mathrm{D} /$ year $v-1.2 \mathrm{D} /$ year). The children in group 2 had a gradual increase in their hyperopia before age 7 years $(+0.27 \mathrm{D} /$ year $)$ and then had a slow decline after age 7 years $(-0.18 \mathrm{D} /$ year) (Fig 6). The overall rate of decline from peak to final refraction was $-0.51 \mathrm{D} /$ year for the children in group 1, which was significantly faster than the overall decline of $-0.07 \mathrm{D} /$ year for the children in group $2(\mathrm{p}=0.014)$.

The median final astigmatic error for group 1 was $+0.18 \mathrm{D}$, compared to $+1.84 \mathrm{D}$ for group $2(\mathrm{p}=0.13)$. Three of the four children in group 2 had greater than +1.50 dioptres of astigmatism at the last follow up examination.

\section{DISCUSSION}

In this study six of $10(60 \%)$ children with accommodative esotropia were able to discontinue spectacle wear after a gradual reduction in their hyperopic correction at a median age of 9 years. In contrast, other studies have reported that only $3-24 \%$ of accommodative esotropes treated in a more conventional manner are able to discontinue spectacle wear when teenagers or adults. ${ }^{3-7}$

Accommodative esotropes may be able to discontinue spectacle use as a result of increased fusional divergence amplitudes, the loss of hyperopia, or a reduction in the synkinesis between accommodation and convergence. In our study, divergence amplitudes increased in all 10 study patients including the four patients who continued to require spectacles. By the end of the study the four patients who continued to require spectacles tolerated a mean undercorrection of their hyperopic refractive error of $1.5 \mathrm{D}$ while still remaining orthotropic. The six children who successfully discontinued spectacle wear also had a reduction in their baseline hyperopia of nearly $0.75 \mathrm{D}(+2.25 v+1.56 \mathrm{D})$ which may have also facilitated their discontinuation of spectacles. In contradistinction, both the control patients and the four study patients who were not able to discontinue spectacle use had an increase in their hyperopia from the baseline to the final examination (controls +3.25 to $+3.88 \mathrm{D}$; study patients +4.50 to $+5.05 \mathrm{D})$. However, despite the increase in their hyperopic refractive error, these four study patients had a reduction in their esotropia without spectacles (35-17 PD) whereas the angle of esotropia of the control patients increased (30-35 $\mathrm{PD})$. This difference presumably reflects their increased divergence amplitudes of the study patients. We did not find a significant change in the ratio of accommodation to convergence among study or control patients.

The study patients who were successfully weaned out of spectacles demonstrated a median loss of hyperopia of $1.75 \mathrm{D}$ from their peak refractive error or $-0.51 \mathrm{D} /$ year. In contrast, Repka $a^{2}$ found only a mean decline in hyperopia of $-0.12 \mathrm{D} /$ year in a large cohort of accommodative esotropes 7 years of age or older (Fig 6). Similarly, Raab ${ }^{1}$ noted a decline in hyperopia of $-0.18 \mathrm{D}$ per year in a group of accommodative esotropes 7-13 years of age. Our control patients experienced a similar rate of decline in their hyperopic refractive error when 7 years of age or older $(-0.12 \mathrm{D} /$ year $)$.

Repka ${ }^{2}$ has postulated that prescribing the full cycloplegic refractive correction may interfere with the emmetropisation of children's eyes. In contrast, Ingram and coworkers ${ }^{8}$ have speculated that an intrinsic defect in the process of emmetropisation may account for the slower loss of hyperopia in accommodative esotropes. In animal studies, optical blur has been shown to affect ocular development and emmetropisation. ${ }^{9-13}$ In a series of experiments performed in infant rhesus monkeys, Smith and Hung ${ }^{9}$ showed that lens induced optical defocus result in compensatory changes in axial growth that reduce the magnitude of the induced refractive error. Monkeys who wore minus lenses experienced a myopic shift arising from increased axial elongation, while monkeys wearing plus lenses became more hyperopic as a result of reduced axial elongation. These results suggest that the growing eye is highly sensitive to the effect of optical defocus and that a spectacle correction may interfere with emmetropisation. Furthermore, full correction of the hyperopic refractive error may blunt emmetropisation more than wearing a partial correction. Gradually weaning the hyperopic correction may leave the eye with a hyperopic defocus, thereby stimulating axial elongation. Non-human primates have been shown to have less ability to compensate for higher levels of lens induced refractive error. ${ }^{11}$ In our study, the children who continued to require glasses were children with higher degrees of baseline hyperopia and astigmatism. Beyond a certain limit, the eye may simply not have the drive or capability to emmetropise.

\section{CONCLUSION}

In this study, we observed that some accommodative esotropes successfully discontinued spectacle wear with resolution of their esotropia during the grade school years. Gradually weaning children out of spectacles may increase the proportion of patients who are able discontinue spectacle wear and it may allow them to discontinue spectacles at an earlier age. Furthermore, even those patients who were not able to discontinue spectacle use had a reduction in their undercorrected angle of esotropia and were able to control their residual esotropia with a reduced hyperopic correction. Whether or not weaning from spectacles, as performed in this study, facilitates emmetropisation remains unresolved. Our pilot study included only a small number of children, and therefore the results must be interpreted with caution. We also recognise that our data suffer from selection bias since this was not a randomised study. We are also uncertain whether binocularity is a prerequisite to successfully wean children 
from spectacles. Wilson and coworkers ${ }^{14}$ have shown that binocularity is an important factor in helping accommodative esotropes maintain their ocular alignment. Since we excluded patients from the present study who lacked binocularity we could not evaluate the role of binocularity in successfully weaning accommodative esotropes out of spectacles.

\section{ACKNOWLEDGEMENTS}

This research was supported in part by a Research to Prevent Blindness, Inc Lew Wasserman Award (SRL) and by a Research to Prevent Blindness unrestricted departmental grant (KAH). Presented in part at the Annual Meeting of the Association for Research and Vision in Ophthalmology, Ft Lauderdale, FL, USA, May 1999.

\section{Authors' affiliations}

K A Hutcheson, N J Ellish, Department of Ophthalmology, University of Maryland School of Medicine, Baltimore, MD, USA

S R Lambert, Emory Eye Center, Emory University, Atlanta, GA, USA

\section{REFERENCES}

1 Raab EL, Spierer A. Persisting accommodative esotropia. Arch Ophthalmol 1986;104:1777-9.

2 Repka MX, Wellish K, Wisnicki HJ, et al. Changes in the refractive error of 94 spectacle-treated patients with acquired accommodative esotropia. Binoc Vis 1989;4:5-21.
3 Swan KC. Accommodative esotropia long range follow-up. Ophthalmology 1983;90:1141-5.

4 Taylor RH, Armitage IM, Burke JP. Fully accommodative esotropia in adolescence. Br Orthopt J 1995:52:25-8.

5 Rutstein RP, Marxh-Tootle W. Clinical course of accommodative esotropia. Optom Vis Sci 1998;75:97-102

6 Raab E. Etiologic factors in accommodative esodeviation. Trans Am Ophthalmol Soc 1982;80:657-94.

7 Kobuta N, Akatsu S. Long-term follow-up of refractive accommodative esotropia. In: Campos EC, ed. Strabismus and ocular motility disorders. London: Macmillan Press, 1990:315-18.

8 Ingram RM, Gill LE, Lambert TW. Effect of spectacles on changes of spherical hypermetropia in infants who did, and did not, have strabismus. Br J Ophthalmol 2000;84:324-6.

9 Smith EL, Hung LF. The role of optical defocus in regulating refractive development in infant monkeys. Vis Res 1999;39:1415-35.

10 Goss DA, Wickham MG. Retinal-image mediated ocular growth as a mechanism for juvenile onset myopia and for emmetropization. Doc Ophthalmol 1995;90:341-75.

11 Smith EL, Hung LF, Harwerth RS. Effects of optically induced blur on the refractive status of young monkeys. Vis Res 1994;34:293-301.

12 Fujikado T, Kawasaki Y, Suzuki A, et al. Retinal function with lens-induced myopia compared with form-deprivation myopia in chicks. Graefes Arch Clin Exp Ophthalmol 1997;235:320-4.

13 Troilo D, Wallman J. The regulation of eye growth and refractive state: an experimental study of emmetropization. Vis Res 1991:31:1237-50.

14 Wilson ME, Bluestein EC, Parks MM. Binocularity in accommodative esotropia. J Pediatr Ophthalmol Strabismus 1993;30:233-6.

\section{New BJO online submission and review system}

The Editors of British Journal of Opthalmology are pleased to inform authors and reviewers of its new online submission and review system. Bench>Press is a fully integrated electronic system which uses the internet to allow rapid and efficient submission of manuscripts, as well as the entire peer review process to be conducted online.

Authors can submit their manuscript in any standard word processing software. Graphic formats acceptable are: .jpg, .tiff, .gif, and eps. (Nb. Multipage PowerPoint presentations are NOT acceptable.) Text and graphic files are automatically converted to PDF for ease of distribution and reviewing purposes. Authors are asked to approve their submission before it formally enters the reviewing process.

To access the system click on "SUBMIT YOUR MANUSCRIPT HERE" on the BJO homepage: http://www.bjopthalmol.com/, or you can access Bench>Press directly at http://submit-bjo.bmijournals.com/.

We are very excited with this new development, it really is simple to use and should be a big improvement on the current peer review process. Full instructions can be found on Bench>Press and BJO online. Please contact Natalie Davies, Project Manager, ndavies@bmigroup.com for further information.

\section{Pre-register}

We would be grateful if all British Journal of Opthalmology authors and reviewers pre-registered with the system. This will give you the opportunity to update your contact and expertise data, allowing us to provide you with a more efficient service.

\section{Instructions For Registering}

1. Enter http://submit-bjo.bmijournals.com

2. Click on "Create a New Account" in the upper left hand side of the Bench>Press

homepage.

3. Enter your email address in the space provided.

4. Choose a password for yourself and enter it in the spaces provided.

5. Complete the question of your choice to be used in the event you cannot remember your password at a later time.

6. Click on the "Save" button at the bottom of the screen.

7. Check the email account you registered under. An email will be sent to you with a verification number and URL.

8. Once you receive this verification number, click on the URL hyperlink and enter the verification number in the relevant field. This is for security reasons and to check that your account is not being used fraudulently.

9. Enter/amend your contact information, and update your expertise data.

10. Please note: You only need to create a new account once. If you submit to another

BM Publishing Group journal you can use the same email address and password 